\title{
Promoting Smart Education, A Medium-Long Term Tool for Reducing Graduate Unemployment in Ghana
}

\author{
Dr. Wahidu Saedu \\ Senior Research Coordinator \&Independent Researcher \\ Ghana Statistical Service (GSS)
}

\begin{abstract}
:
The traditional educational system has ended up producing mostly products of pen pushers (Prof. Nsowah Nuamah, 2005). The modern educational system must not only be directed towards the development of the arms of future specialists by professional knowledge and abilities, but also on formation of free creative thinkers, requirement to continuous self-education needful for the required innovation in the business world. This research work is devoted to one of actual problems in education to a problem of search of innovative approaches in formation of creative thinking of students. In a generalized view, creativity discussed as ability to put forward original, nonstandard ideas, to apply various strategy in the solution of problems, readiness to develop the arisen ideas. "Creativity" is understood by many researchers as deviation from the status quo way of approach. The "chew and pour'" system of education has produced what is termed as graduates of mass destruction in the industrial world.

Special attention must be paid on the independent activities of students, definite purposes and problems of this kind of activity. As the leading tasks are allocated: formation of independent thinking, ability to self-development, self-improvement, self-realization; development of a creative initiative, skills of research; motivation of purposeful work on enrichment of the general and professional knowledge. Whilst the traditional educational system places much emphasis on IQ the modern day requisites for meeting the needs of Business Management are Emotional Quotient (AQ) and Adversity Quotient. Whilst the business world operates on the tenets of conscious capitalism (Dr. Amber Gove is Director of Research within RTI's International Education Division) the educational system must ensure to retool the thinking capacities of students. In the conclusion, it is noted that, according to vast majority of the interrogated teachers, the problem of development of creative identity of students is non-negotiable because the captains of industry require nothing short of this. This research work is geared towards driving this clarion call.
\end{abstract}

Key words: Adversity quotient; Conscious capitalism; Creative thinking; Critical thinking; Professional Knowledge 